\title{
Sonographic variations in common bile duct dimensions
}

\author{
B. Raj Joshi \\ Department of Radiology and Imaging, Tribhuvan University Teaching Hospital, Kathmandu, Nepal. \\ Correspondence to: B. Raj Joshi \\ Department of Radiology and Imaging,Tribhuvan University Teaching Hospital, Kathmandu, Nepal. \\ Email: bjoshi01@yahoo.com
}

\begin{abstract}
Introduction: Biliary diseases such as cholelithiasis, cholecystitis, hepatitis, cirrhosis and pancreatitis are common in Nepal. Cholelithiasis was present in 8 percent of the emergency patients, second to acute appendicitis. Acute cholecysistitis was present in 25 percent of these patients. ${ }^{1}$ The most common operation in a district hospital was cholecystectomy (31\%]). ${ }^{2}$ Ultrasound plays an integral part in evaluation of biliary system. The aim of the study was also to determine whether the size of the CBD increases with age.

Methods: We prospectively collected data on 100 patients aged 15 years or older who underwent abdominal sonography. The subjects had no history of biliary and pancreatic disease or operation. The CBD was measured in porta hepatis, in the distal aspect of head of pancreas and midway between these points. Linear regression was used to correlate age with the dimension.

Results: There were 30 males and 70 females in the study. The subjects ranged from 15 to 80 years. The mean diameters were as follows: $3.76 \mathrm{~mm}$ in proximal, $4.26 \mathrm{~mm}$ in middle, $4.90 \mathrm{~mm}$ in distal portion of CBD. The overall measurement was $4.23 \mathrm{~mm}$.

Conclusions: There was a significant correlation between CBD size and age. Correlation with age was best observed for the distal segment.

Keywords: Biliary diseases, CBD, ultrasound.
\end{abstract}

\section{Introduction}

Biliary diseases such as cholelithiasis, cholecystitis, hepatitis, cirrhosis and pancreatitis are common in Nepal. Cholelithiasis was present in 8 percent of the emergency patients, second to acute appendicitis. Acute cholecysistitis was present in 25 percent of these patients. ${ }^{1}$ The most common operation in a district hospital was cholecystectomy (31\%). Cholecystectomy with exploration of CBD was $9 \%$. ${ }^{2}$ Ultrasound plays an integral part in evaluation of biliary system. In $1984 \mathrm{Wu}$ et al reported that the diameter of CBD increases normally by $1 \mathrm{~mm}$ every decade. Other sonographic studies established $4 \mathrm{~mm}$ as normal mean CBD diameter at age of 40 years, $5 \mathrm{~mm}$ at 50 years and $8 \mathrm{~mm}$ at 80 years. ${ }^{3-6} \mathrm{In} 2003$ Bachar ${ }^{7}$ published that the width of CBD ranged from 1-8.6 and it dilated 0.04 $\mathrm{mm} /$ year. Horrow and associates ${ }^{8}$ observed no increase in CBD with age. Until now no study has been conducted to determine the normal dimension in Nepalese population. The aim of the study was also to determine whether the size of the CBD increases with age.

\section{Methods}

The study was performed on hundred patients who came to the author's department from $1^{\text {st }}$ January to 30th June 2009 for abdominal sonography. The subjects who had liver , biliary and pancreatic disease or operation of biliary system 


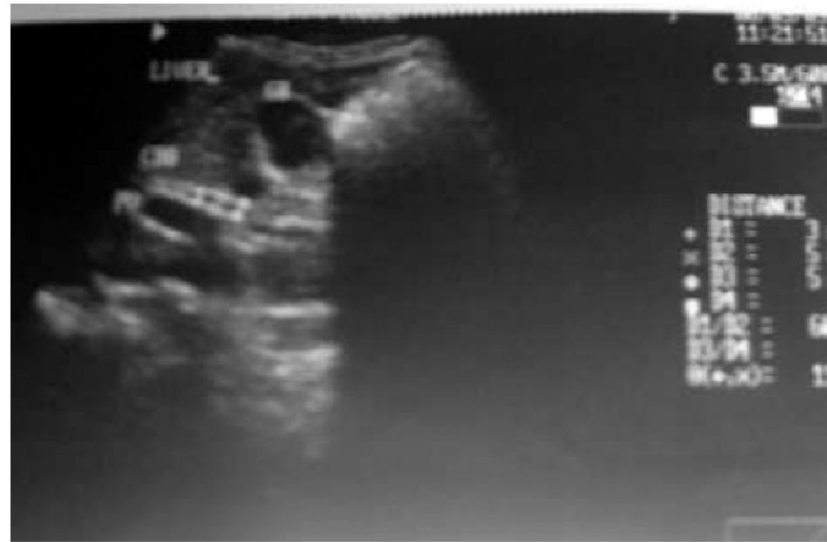

Fig. 1: $C B D$ in anterior relation to portal vein

were excluded. Persons with abnormal serum bilirubin, alkaline phosphatase, SGPT, SGOT were excluded in addition to patients taking smooth muscle relaxant medication.

The sonographic scan was performed after 6 hours of fasting. The examination was performed during deep inspiration in the supine or left lateral oblique position by a right subcostal approach. The CBD was identified at the level of portal vein, where the hepatic artery crosses perpendicularly between them. Colour Doppler was used to confirm the identification of these. The extrahepatic bile duct was measured at 3 locations ; in the porta hepatis, in the most distal aspect of the head of pancreas and midway between these points. Inner border to inner border in anteroposterior dimension were obtained for each of these locations using electronic calipers (Fig. 2).

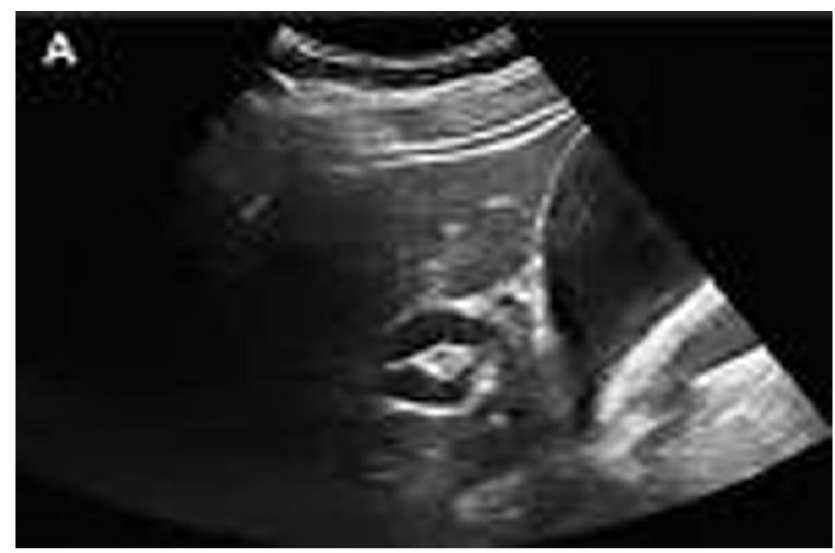

Fig. 2: Measurement of extrahepatic bile duct at 3 locations; in the porta hepatis, in the most distal aspect of the head of pancreas and midway between these points. Inner border to inner border in antero-posterior dimension are obtained for each of these locations using electronic calipers.

Linear regression was used to correlate patient's age and size of CBD. Age was used as independent variable while the mean diameter was used as the dependent variable. $\mathrm{P}$ value of less than 0.05 was used as significant.

\section{Results}

There were 30 males and 70 females in the study. The subjects ranged from 15 to 80 years. The mean diameters were as follows: $3.76 \mathrm{~mm}$ in proximal, $4.26 \mathrm{~mm}$ in middle, $4.90 \mathrm{~mm}$ in distal portion of CBD.

\begin{tabular}{|c|c|c|c|c|c|}
\hline \multicolumn{6}{|c|}{ Correlations } \\
\hline & & AGE & DISTAL & PROX & MID \\
\hline \multirow[b]{2}{*}{ AGE } & Pearson Correlation & 1 & $.480(* *)$ & $.360(*)$ & $.303(*)$ \\
\hline & Sig. (2-tailed) & . & .000 & .011 & .034 \\
\hline \multirow[b]{2}{*}{ DISTAL } & Pearson Correlation & $.480(* *)$ & 1 & $.517(* *)$ & $.649(* *)$ \\
\hline & Sig. (2-tailed) & .000 & . & .000 & .000 \\
\hline \multirow[b]{2}{*}{ PROX } & Pearson Correlation & $.360(*)$ & $.517(* *)$ & 1 & $.492(* *)$ \\
\hline & Sig. (2-tailed) & .011 & .000 & . & .000 \\
\hline \multirow[b]{2}{*}{ MID } & Pearson Correlation & $.303(*)$ & $.649(* *)$ & $.492(* *)$ & 1 \\
\hline & Sig. (2-tailed) & .034 & .000 & .000 & . \\
\hline \multicolumn{6}{|c|}{ ** Correlation is significant at the 0.01 level (2-tailed). } \\
\hline \multicolumn{6}{|c|}{ * Correlation is significant at the 0.05 level (2-tailed). } \\
\hline
\end{tabular}

Table 1: Relation between CBD and age

The overall measurement was $4.23 \mathrm{~mm}$. There was a significant correlation between CBD size and age. Correlation was best observed for the distal segment with age.

\section{Dicussion}

In $1984 \mathrm{Wu}$ et $\mathrm{al}^{3}$ established the effect of age on the size of the extrahepatic bile duct. The sizes ranged from 1-10mm and were age dependent. Bowei ${ }^{4}$ suggested that the upper limit of the normal CBD should be considered $7 \mathrm{~mm}$. There is considerable increase in the CBD diameter in elderly subjects in comparison with younger populations.

Perret ${ }^{5}$ evaluated CBD in subjects aged 60-96 years and found significant increase with age. Kaim ${ }^{6}$ reported CBD size from 2.1- $9.5 \mathrm{~mm}$ in subjects of $45-75$ years. In 2003 Bacher et $\mathrm{al}^{7}$ showed significant correlation between CBD size and age $[\mathrm{r}=0.535 ; \mathrm{p}<0.001 ; \mathrm{r} 2=0.28]$. They found significant difference between the group younger than 50 and older than 51 years; 3.13 versus 4.19 [p $<0.001]$. The duct gradually dilated $0.04 \mathrm{~mm} /$ year. They suggested $8.5 \mathrm{~mm}$ 
as the upper limit of normal CBD in elderly patients.

But Hollow et $\mathrm{al}^{8}$ failed to observe any increase in CBD size with age. The age was not uniformly distributed in this study. Kaude ${ }^{9}$ reported CBD size from 2.8 to $4.1 \mathrm{~mm}$ in subjects of 20-71 years. Barthet ${ }^{10}$ noted significant correlation of biliary duct diameter with age by analyzing cholangiograms obtained by endoscopic retrograde cholangiopancreatography. The CBD gradually widens from the porta hepatis to the head of the pancreas. The enlargement in elderly patients is due to the characteristic fragmentation of the longitudinal smooth myocyte bands and interspersed connective tissue combined with decrease in the reticular-elastic framework. This leads to reduced contractility and hypotonus of the CBD. Drugs such as calcium-blockers and nitroglycerine may influence the contractility and tonus of the duct wall. ${ }^{11}$

\section{Conclusions}

The conclusions of the study were that the normal range of CBD in Nepalese population is 2-7 $\mathrm{mm}$ and the study showed an age-dependent change in the diameter.

\section{References}

1. Joshi BR,Pradhan S, Ansari MA. Problems regarding emergency ultrasound in Nepal. JIOM 2008;30:2-5

2. Joshi BR. Wound infection after abdominal surgery.JNMA 1991;29;210-214

3. Wu Cc, Ho YH, Chen CY. Effect of aging on common. bile duct diameter: a real time ultrasonographic study. J Clin Ultrsaound 1984; 12: 473-478.

4. Bowie JD. What is the upper limit of normal for the common bile duct on ultrasound? How much do you want it to be? Am I Gastoenterol 2000; 95: 897-900.

5. Perret RS, Sloop GD, Borne JA. Common bile duct measurements in an elderly population. I Ultrasound Med 2000; 19: 727-730.

6. Kaim A, Steinke K, Frank M, et al. Diameter of the common bile duct in the elderly patient: measurement by ultrasound Eur Radiol 1998; 8: 1413-1415.

7. Bachar GB, Cohen M, Belenky A et al Effect of aging on the adult extrahepatic bile duct, J ultrasound in Med, 2003; 9: 879-882.

8. Horrow MM, Horrow JC, Niakosari A, et al. Is age associated with size of the adult extrahepatic bile duct: sonographic study.Radiology 2001; 221: 411-414.
9. Kaude JV. The width of the common bile duct in relation to age and stone disease: an ultrasonographic study. Eur J Radiol 1983; 3: 115-117.

10. Barthet M, Spinoza S, Affriat C, et al. Influence of age and biliary lithiasis on the diameter of common bile duct. Gastroenterol Clin Biol 1995; 19: 156-160.

11. Parulekar SG. Ultrasound evaluation of common bile duct size. Radiology 1979; 133: 703-707. 